\title{
CFTR transcripts are undetectable in lymphocytes and respiratory epithelial cells of a CF patient homozygous for the nonsense mutation R553X
}

Katrin Will, Jochen Reiss, Michael Dean, Manfred Schlösser, Ryzard Slomski, Jörg Schmidtke, Manfred Stuhrmann

\begin{abstract}
In order to analyse the influence of the nonsense mutation R553X on CFTR gene expression, transcripts from epithelial cells and lymphocytes were examined from nine subjects (one CF patient homozygous for R553X, one CF patient compound heterozygous for $\mathbf{R 5 5 3 X} /$ $\Delta F 508$, four CF carriers heterozygous for $\mathbf{R 5 5 3 X}$, one CF carrier with the genotype $\Delta F 508 / N$, and two uncharacterised normal adults). After reverse transcription of the region from exons 10 to 13 to cDNA, fragments of the expected size were amplified from all heterozygous and normal subjects. In three subjects an additional alternatively spliced product was observed, which was found to contain a termination codon. In repeated experiments it was not possible to detect any CFTR mRNA in cells derived from the R553X homozygous patient. Furthermore, in subjects heterozygous for $\mathbf{R 5 5 3 X}$ we could not detect by hybridisation with a specific oligonucleotide probe and direct sequencing any CFTR mRNA derived from the R553X allele. However, the wild type product was present in all of these subjects. Our results support the view that nonsense mutations in the CFTR gene can lead to a reduction or absence of cytoplasmic CFTR mRNA. (f Med Genet 1993;30:833-7)
\end{abstract}

Genetics,

Medizinische

Hochschule Hannover, Germany.

$\mathrm{K}$ Will

J Schmidtke

M Stuhrmann

Institute of Human

Genetics, Universität

Göttingen, Germany.

J Reiss

M Schlösser

R Slomski

Laboratory of Viral Carcinogenesis, National Cancer Institute, Frederick

Cancer Research and Development Center, Bldg 560/Rm 21-19, Frederick, MD 21702-1201, USA.

$M$ Dean

Correspondence to Dr Dean

Received 28 January 1993. Revised version accepted 11 May 1993.

Cystic fibrosis (CF) is one of the most common autosomal recessive disorders in white populations. In CF patients, abnormal chloride secretion across the apical membrane of the epithelial cells causes clinical symptoms, including chronic pulmonary disease and pancreatic exocrine insufficiency, together with an increase in the concentration of sweat electrolytes. ${ }^{1}$ The gene responsible for $\mathrm{CF}$, the cystic fibrosis transmembrane conductance regulator (CFTR) gene, is located on chromosome 7q31 and has been cloned and sequenced. ${ }^{23}$ The CFTR protein shows structural similarities to the members of the ATP binding transporter family. The function of CFTR is not completely understood, but the results of experiments involving expression of normal CFTR in human, rodent, and insect cells suggest that CFTR itself is a chloride channel. ${ }^{45}$ Over 200 different mutations in the CFTR gene associ- ated with the CF phenotype have been reported so far (Cystic Fibrosis Genetics Analysis Consortium, June 1992). The most frequent mutation, $\Delta \mathrm{F} 508,{ }^{6}$ located in the first nucleotide binding fold, is usually associated with severe $\mathrm{CF},{ }^{7}$ but in exceptional cases $\Delta \mathrm{F} 508$ homozygotes are only mildly affected. ${ }^{8}$

Three nonsense mutations, G542X, ${ }^{9}$ $\mathrm{R} 553 \mathrm{X},{ }^{10}$ and W1282X, ${ }^{11}$ represent the second, fourth, and fifth most frequent CF mutations worldwide (Cystic Fibrosis Genetics Analysis Consortium, unpublished data). Until now, only a few cases of homozygosity for nonsense mutations or compound heterozygosity for two nonsense mutations have been reported. Two CF patients, homozygous for the G542X mutation, have been described as mildly affected. ${ }^{12}$ Cutting et $a l^{14}$ found two patients heterozygous for W1316X/R553X and S1255X/G542X, respectively, to exhibit severe pancreatic but only mild pulmonary disease. In contrast, Shoshani et al ${ }^{15}$ showed that the most common CF mutation in the Ashkenazi Jewish population, W1282X, which is located in exon 20 , is clearly associated with a severe phenotype. We previously classified the only known homozygous R553X patient as being moderately severely affected. ${ }^{16} \mathrm{We}$ report here on CFTR mRNA analysis in this patient, who is homozygous for R553X (a CGA to TGA substitution at position 1789 in exon 11 of the CFTR gene), and in R553X heterozygotes, in order to investigate the influence of nonsense mutations on gene expression.

\section{Methods}

FAMILY A

Case 1 was a 15 year old male CF patient of German origin, who was homozygous for the stop mutation $\mathrm{R} 553 \mathrm{X}$, with severely reduced pancreatic function, but only mildly affected lung function. His height was normal, but his weight ranged between the $3 \mathrm{rd}$ and the 10 th centile. We have previously described the clinical features of this patient in greater detail. ${ }^{16}$ Case 2 was a male CF carrier (R553X) of German origin. He was a symptomless adult and the father of case 1 and a second cousin of case 3. Case 3 was a female CF carrier (R553X) of German origin. She was a symptomless adult and the mother of case 1 and a second coủsin of case 2 . 
FAMILY B

Case 4 was a 6 year old male CF patient of German origin and a compound heterozygote for $\Delta \mathrm{F} 508$ and R553X, with insufficient pancreatic function and recurrent pneumonia. His weight is below the 3rd centile, while his height is normal. We classify this patient as being severely affected. Case 5 was a male CF carrier $(\Delta \mathrm{F} 508)$ of German origin. He was a symptomless adult and the father of case 4 . Case 6 was a female CF carrier (R553X) of German origin. She was a symptomless adult and the mother of case 4.

\section{CONTROLS}

Case 7 was a male CF carrier (R553X) of American origin and was a symptomless adult. Case 8 was a female of German origin and was a symptomless adult. Case 9 was a male of Polish origin and was a symptomless adult

From cases 1, 3, 4, 5, 6, 8, and 9 nasal epithelial cells were obtained by brushing and blood was also collected from these persons. Lymphocytes were obtained from case 2 (from fresh blood) and case 7 (from a lymphoblastoid cell culture).

\section{RNA EXTRACTION AND cDNA SYNTHESIS}

Cells obtained by brushing were either transferred to culture medium, centrifuged, washed with PBS, and resuspended in $4 \mathrm{~mol} / 1$ guanidinium thiocyanate buffer (GTC), or were placed directly into $4 \mathrm{~mol} / 1 \mathrm{GTC}$. Total RNA was extracted from pelleted lymphocytes and epithelial cells using the guanidinium thioisocyanate method. ${ }^{17}$ To control the mRNA quality, aliquots of all samples were reverse transcribed to CDNA using a primer within (1) the multidrug resistance (MDR1) gene and (2) the $\beta 2$-microglobulin $(\beta 2 \mathrm{~m})$ gene and afterwards amplified with primers located in appropriate regions of these genes. ${ }^{18}$ Only mRNA preparations from which fragments of the expected size could be amplified were used in the following experiments. A control transcription of a sample without RNA was included in each cDNA synthesis.

For reverse transcription of CFTR mRNA primer $13 c$ (the sequences of the oligonucleotides used in this study are listed in the table) was used. Total RNA $(5 \mu \mathrm{g})$ or mRNA $(0.5 \mu \mathrm{g})$ were specifically converted to cDNA. We followed the reverse transcription protocol suggested for the GeneAmpRNA PCR Kit (Perkin Elmer Cetus) and incubated $20 \mu \mathrm{l}$ cDNA reaction mixture (including $2 \mathrm{U}$ AmpliTaq DNA polymerase) in a Perkin-Elmer Cetus

$D N A$ sequence of the oligonucleotides used for reverse transcription $(R T)$, polymerase chain reaction (PCR), and allele specific oligonucleotide (ASO) hybridisation.

\begin{tabular}{llr}
\hline Oligonucleotide & \multicolumn{1}{c}{ Sequence } \\
\hline 13c & 5-GTCGAAAGAATCACATCCCATGA-3 & \\
13MS & 5-TCACATCCCATGAGTTTTGAGCT-3 & (RT, PCR) \\
8a & 5-GTAGTGATGGAGAATGTAACAGCC-3 & (PCR) \\
9MF & 5-TGTAAAACGACGGCCAGTAATGGTGATGACAGC-3 & (PCR) \\
10c & 5-GTTTTCCTG \\
R553X mutant & 5-GGAGGTCAATGTATGCCTGGCACC & (PCR) \\
R553X wild type & 5-GGAGGTCAACGAGCA-3 & (ASO) \\
\hline
\end{tabular}

DNA Thermal Cycler at $42^{\circ} \mathrm{C}$ for 15 minutes, $99^{\circ} \mathrm{C}$ for five minutes, and $5^{\circ} \mathrm{C}$ for five minutes.

'NESTED' POLYMERASE CHAIN REACTION (PCR) An initial PCR was performed with $20 \mu$ l cDNA, primers $8 \mathrm{a}$ and $13 \mathrm{c}(30 \mathrm{pmol}$ each $), 5 \mu \mathrm{l}$ $10 \times$ Taq buffer, 2.5 U Taq polymerase (Stratagene), and $0.5 \mu \mathrm{l} 20 \mathrm{mmol} / 1$ (each) dNTP (Boehringer) in a total volume of $50 \mu$ l under the following conditions: 10 minutes' denaturation at $94^{\circ} \mathrm{C}, 35$ cycles consisting of one minute denaturation at $94^{\circ} \mathrm{C}$, one minute annealing at $55^{\circ} \mathrm{C}$, and three minutes' extension at $72^{\circ} \mathrm{C}$. Final extension was at $72^{\circ} \mathrm{C}$ for 10 minutes. Under identical conditions, two nested amplifications were performed on a fixed aliquot $(5 \%)$ of the total PCR volume with the primer combinations $13 \mathrm{MS} / 9 \mathrm{MF}$ and $13 \mathrm{MS} / 10 \mathrm{c}$. Ten percent of the total PCR reaction was electrophoresed through a $0 \cdot 8 \%$ agarose gel stained with ethidium bromide.

SEQUENCING OF THE AMPLIFIED CDNA

The PCR products were size fractionated on an $8 \%$ polyacrylamide gel in $1 \times$ TBE buffer. The bands were cut out and eluted overnight in distilled water at $60^{\circ} \mathrm{C}$. Under the conditions described above, the cDNA was subjected to an asymmetrical PCR reaction (primers $13 \mathrm{MS} / 10 \mathrm{c}$ with a ratio of 100:1). After centrifugation of the PCR products through Centricon-100 columns, direct sequencing with Sequenase (USB) was carried out according to the manufacturer's instructions.

\section{ALLELE SPECIFIC OLIGONUCLEOTIDE (ASO)} HYBRIDISATION

The amplified cDNA from all probands was dot blotted to nylon membranes (Hybond $\mathrm{N}+$, Amersham) according to standard procedures. ${ }^{19}$ Filters were prehybridised for one hour at $60^{\circ} \mathrm{C}$ (ASO for wild type allele) and $62^{\circ} \mathrm{C}$ ( $\mathrm{R} 553 \mathrm{X}$ mutation specific ASO) in a hybridisation solution containing $5 \times \mathrm{SSPE}$, $5 \times$ Denhardt's solution, and $0.5 \%$ Triton $X$ 100 . The labelling reaction of the oligonucleotides was performed at $37^{\circ} \mathrm{C}$ for 30 minutes. The labelling mixture included $10 \mu$ l oligonucleotide $(10 \mathrm{D} / \mathrm{ml}), 3 \mu \mathrm{l} 10 \times$ kinase buffer, $15 \mu \mathrm{l}$ ${ }^{32} \mathrm{P} \mathrm{dATP}$, and $2 \mu \mathrm{l} \mathrm{T} 4$ polynucleotide kinase (Boehringer). After prehybridisation, the filters were hybridised at the same temperature for one hour. The filters were washed once at room temperature with a $2 \times$ SSPE, $0.1 \%$ Triton X-100 solution for two minutes followed by a final wash with the same solution for 15 minutes at $60^{\circ} \mathrm{C}$ and $62^{\circ} \mathrm{C}$, respectively. Subsequently the filters were exposed to $x$ ray film for one hour. As positive controls, PCR products including exon 11 , amplified with primers $11 \mathrm{i}-5$ and $11 \mathrm{i}-3^{20}$ from genomic DNA of a R553X carrier, a patient homozygous for R553X, and a normal adult were blotted and hybridised. 


\section{Results}

We converted CFTR mRNA from lymphocytes and nasal epithelial cells to cDNA and amplified the region from exons 10 to 13 by PCR. Since the amount of CFTR transcripts in 'non-expressing' tissues such as lymphocytes is very low, we used the 'nested' PCR approach (fig 1). With the exception of the R553X homozygous patient (lane 5), cDNA amplification was possible from all nasal epithelial cells and lymphocytes that were attempted. Fragments of three different lengths, measuring 583, 464, and $377 \mathrm{bp}$, were seen (fig 2). All PCR products were analysed by direct sequencing. The $464 \mathrm{bp}$ fragment was identified as the expected normal splice product. The $583 \mathrm{bp}$ product was found to be the result of alternative splicing and included a $119 \mathrm{bp}$ insert with a stop codon. We have previously shown ${ }^{21}$ that the occurrence of the

A CFTR normal transcripts

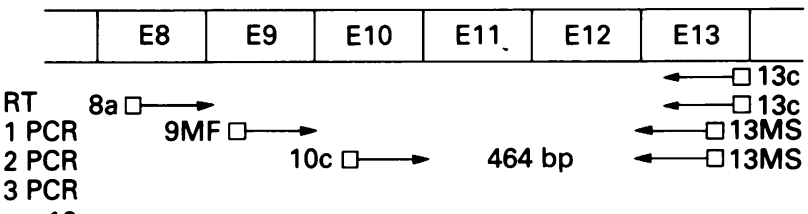

B Deletion of exon 12

3 PCR

\begin{tabular}{c|c|c|c|c|c|c}
\hline & E8 & E9 & E10 & E11 & E13 & \\
\hline \multicolumn{3}{c}{ 10c $\square$ 377 bp $\square$ - $\square$ 13MS }
\end{tabular}

C Insertion of a 119 bp fragment

\begin{tabular}{l|l|l|l|l|l|l|l|l}
\hline & E8 & E9 & E10 & 119 & E11 & E12 & E13 & \\
\hline 3 PCR & \multicolumn{8}{c|}{$583 \mathrm{bp}$}
\end{tabular}

Figure 1 Schematic representation of the 'nested' PCR approach. Total RNA was converted to $c D N A$ using primer $13 c$ and amplified by 'nested' $P C R$ with the primer sets $8 a / 13 c, 9 M F / 13 M S$, and 10c/13MS. (A) CFTR PCR products of the expected size (464 bp) include parts of exon 10, exon 11, exon 12, and exon 13 . (B) In the $377 \mathrm{bp} P C R$ product, exon 12 is deleted. (C) The $583 \mathrm{bp}$ alternative spliced fragment contains a $119 \mathrm{bp}$ insertion directly between exon 10 and exon 11 .

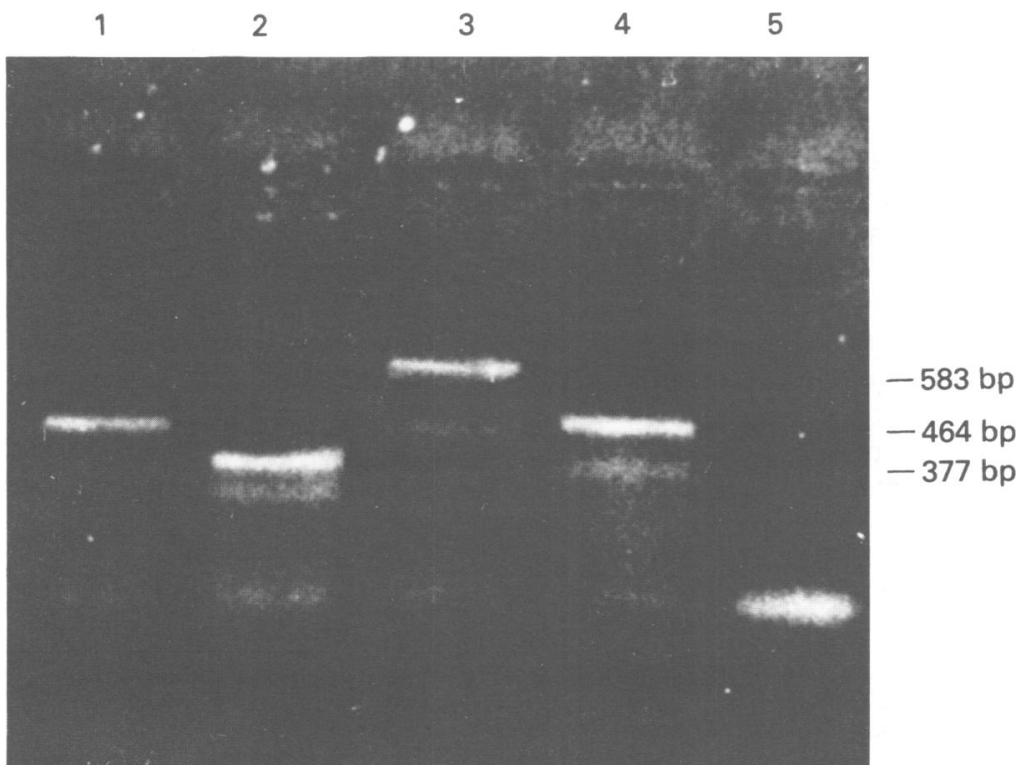

Figure 2 Alternative splicing in the first nucleotide binding fold of CFTR. (A) $0.8 \%$ agarose gel of 'nested' PCR products amplified from the $R 553 X$

homozygous patient (lane 5), the patient's mother (lane 3), the patient's father (lane 4), and two healthy controls (lanes 1 and 2). Products of $583 \mathrm{bp}, 464 \mathrm{bp}$, and $377 \mathrm{bp}$ in size are visible. The 583 bp product included a $119 \mathrm{bp}$ insert between exons 10 and 11. The 464 bp fragment represents the expected, normally spliced product. In the 377 bp fragment, exon 12 is missing. In lane 5, the primers are present (bottom), but no amplification product is detectable. splice variant appears to be independent of the CFTR genotype. In the 377 bp fragment, exon 12 is missing. Exon 12 skipping, accounting for over $90 \%$ of the detectable mRNA, has been previously reported..$^{22} 23$ In repeated experiments, it was not possible to detect any CFTR cDNA from the R553X homozygous patient on ethidium bromide stained agarose gel. This indicates a severe reduction or even absence of the CFTR mRNA in the homozygous patient. Control RT-PCR experiments using primers from within the multidrug resistance gene (MDR1) and the $\beta 2$-microglobulin gene $(\beta 2 \mathrm{~m})$ showed that the mRNA from this patient was intact. In order to increase the level of detection sensitivity, we performed allele specific oligonucleotide (ASO) hybridisations for the R553X and normal alleles. As shown in fig 3, only the CFTR exon 11 controls, amplified from genomic DNA of homozygotes and heterozygotes for R553X, hybridised to the R553X mutant oligonucleotide. CFTR exon 11 DNA of a person heterozygous for R553X hybridised to both the wild type and the mutant oligonucleotides. The wild type ASO hybridised to the amplified cDNA from the region of exons 10 to 13 from the normal and heterozygous subjects. The PCR reaction from the homozygous patient hybridised to neither the normal nor the R553X ASO. Furthermore, by direct sequencing of the PCR products of heterozygotes from mRNA of both nasal epithelial cells and lymphocytes only the wild type sequence was obtained. These results show that the levels of CFTR transcripts carrying the R553X mutation are severely reduced or even absent in both tissues.

\section{Discussion}

We show here that patients, either homozygous or heterozygous for the nonsense mutation R553X, have no detectable CFTR mRNA derived from the R553X allele in nasal epithelial cells and lymphocytes. This observation is in accordance with previous findings of Hamosh et $a l^{24}$ and Jones et $a l^{25}$ for other nonsense mutations within the CFTR gene. Furthermore, a number of nonsense mutations in other eukaryotic genes (CYP21B gene, $\beta$ globin gene, insulin receptor gene) have been shown to be associated with a severely reduced and thereby undetectable mRNA level. ${ }^{26-28}$ The mechanisms by which nonsense mutations reduce the cellular mRNA levels are not well understood. A lower transcription rate, a lower rate of RNA processing including a rapid destruction of unstable intermediates, a reduced transport from spliced mRNA, or a decreased stability of mature mRNA have all been discussed.

Sequence changes have been shown to affect the stability of mRNA in bacteria and yeast. ${ }^{29}$ However, Urlaub et $a l^{30}$ have ruled out an increased lability of dihydrofolate reductase mRNA in eukaryotic cells carrying stop codon mutations. Moreover, these authors observed the 'polar' effect that nonsense mutations within the first exons of this gene lead to 


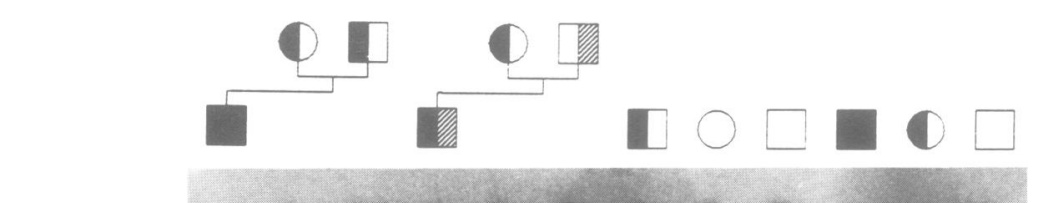

Normal

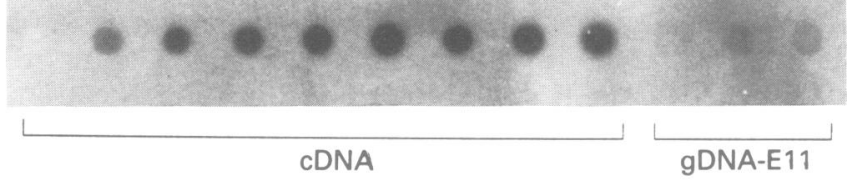

cDNA

Figure 3 Allele specific oligonucleotide hybridisation ( $A S O$ ) for the $R 553 X$ and normal alleles. Each membrane was dotted with amplified cDNAs from all subjects (subjects 1 to 9 from left to right) and PCR products including exon 11, amplified with primers $11 i-5$ and $11 i-3^{20}$ from genomic DNA of the R553X homozygous patient, a $R 553 X$ carrier, and a normal adult. Hybridisation was carried out with an ASO for the wild type allele (normal) and a R553X mutation specific ASO (R553X). Solid symbols: R553X, hatched symbols: $\triangle F 508$, open symbols: normal.

drastically reduced intracytoplasmic levels of dihydrofolate reductase mRNA, whereas stop codon mutations in the last exon result in normal mRNA levels. It was possible to restore normal RNA levels in revertants of low RNA nonsense mutants by substitution of the nonsense mutants through missense mutants. ${ }^{30}$ This finding suggests that the low mRNA level is a functional consequence of the nonsense codons and not caused by a change in mRNA secondary structure. If stop codon mutations, such as R553X, within the first half of the CFTR gene, generally lead to severely reduced or even absent intracytoplasmic mRNA levels, it is surprising that the $583 \mathrm{bp}$ splice variant carrying a stop codon within the same region appears to be rather stable ${ }^{21}$ (this study). Our data suggest the existence of special recognition signals of the post-transcriptional process (for example, for transport from the nucleus into the cytoplasm), which are not affected by the stop codon of the splicing variant.

In summary, we assume that an association exists between the intracytoplasmic mRNA level and the phenotype. The patients seem to be less severely affected if, because of homozygosity or compound heterozygosity for nonsense mutations, the intracytoplasmic mRNA is reduced or absent. However, this view may be biased because of the small number of patients studied in this respect. Transcription studies of patients homozygous for the stop mutation W1282X within exon 20 of the CFTR gene (that is, its $3^{\prime}$ end), which is associated with a severe phenotype,,$^{15}$ as well as mRNA analysis of other patients homozygous for nonsense mutations will help to come to a better understanding of the relationship between the location of nonsense mutations, and their influence on the mRNA level and the clinical phenotype.

We thank C Stewart and B Gerrard, PRI/
DynCorp, Frederick, Maryland, for technical assistance. This work was supported by the Deutsche Forschungsgemeinschaft and by the Deutsche Gesellschaft zur Bekämpfung der Mukoviszidose.

1 Frizell RA, Rechenkemmer G, Shoemaker RL. Altered regulation of airway epithelial cell chloride channels in cystic fibrosis. Science 1986;233:558-60.

2 Rommens JM, Iannuzzi ML, Kerem BS, et al. Identification of the cystic fibrosis gene: chromosome walking and tion of the cystic fibrosis gene: chro
jumping. Science 1989;245:1059-65.

3 Riordan JR, Rommens JM, Kerem BS, et al. Identification of the cystic fibrosis gene: cloning and characterization of of the cystic fibrosis gene: cloning and characterizatior
complementary cDNA. Science 1989;245:1066-73.

4 Anderson MP, Rich DP, Gregory RJ, et al. Generation of cAMP-activated chloride currents by expression of CFTR. Science 1991;251:679-82.

5 Kartner N, Hanrahan JW, Jenson TJ, et al. Expression of the cystic fibrosis gene in non-epithelial invertebrate cells produces a regulated anion conductance. Cell 1991;64:681-91.

6 Kerem BS, Rommens JM, Buchanan JA, et al. Identification of the cystic fibrosis gene: genetic analysis. Science 1989;245:1073-80.

7 Kerem BS, Zielinski J, Markiewicz D, et al. Identification of mutations in regions corresponding to the two putative nucleotide (ATP)-binding folds of the cystic fibrosis gene. Proc Natl Acad Sci USA 1990;87:8447-51.

8 Stuhrmann M, Macek M Jr, Reis A, et al. Genotype analysis of cystic fibrosis patients in relation to pancreatic analysis of cystic fibrosis patients
sufficiency. Lancet 1990;i:738-9.

9 Kerem E, Corey M, Kerem BS, et al. The relation between genotype and phenotype in cystic fibrosis-analysis of the most common mutation $(\Delta \mathrm{F} 508)$. N Engl $f \mathrm{Med}$ 1990;323:1517-22.

10 Cutting GR, Kasch LM, Rosenstein BJ, Tsui LC, Kazazian $\mathrm{HH}$, Antonarakis SE. Two patients with cystic fibrosis nonsense mutations in each cystic fibrosis gene, and mild pulmonary disease. $N$ Engl $\mathcal{f}$ Med 1990;323:1686-9.

11 Vidaud M, Fanen P, Martin J, Ghanem N, Nicolas S, Goossens $M$. Three mutations in the CFTR gene in French cystic fibrosis patients: identification by denaturing gradient gel electrophoresis. Hum Genet 1990;85:4469.

12 Cuppens $\mathrm{H}$, Marynen $\mathrm{P}$, De Boeck $\mathrm{C}$, et al. A child, homozygous for a stop codon in exon 11, shows milder homozygous for a stop codon in exon 11 , shows milder cystic fibrosis symptoms tha

13 Beaudet AL, Perciaccante RG, Cutting GR. Homozygous nonsense mutation causing cystic fibrosis with uniparental disomy. Am f Hum Genet 1991;48:1213.

14 Cutting GR, Kasch LM, Rosenstein BJ, et al. A cluster of cystic fibrosis mutations in the first nucleotide-binding fold of the cystic fibrosis conductance regulator protein. Nature 1990;346:366-9.

15 Shoshani T, Augarten A, Gazit E, et al. Association of a nonsense mutation (W1282X), the most common mutation in the Ashkenazi Jewish cystic fibrosis patients in Israel, with presentation of severe disease. Am $\mathcal{F ~ H u m}$ Genet 1992;50:222-8.

16 Bal J, Stuhrmann M, Schlösser M, Schmidtke J, Reiss J. A cystic fibrosis patient homozygous for the nonsense mutation R553X. ₹ Med Genet 1991;28:715-17.

17 Chomczynski P, Sacchi N. Single-step method of RNA isolation by acid guanidium thiocyanate-phenol-chloroisolation by acid guanidium thiocyanate-pheno

18 Noonan KE, Beck C, Holzmayer TA, et al. Quantitative analysis of MDR1 (multidrug resistance) gene expression in human tumors by polymerase chain reaction. Proc Nat Acad Sci USA 1990;87:7160-4.

19 Saiki RL, Chang C, Levenson CH, et al. Diagnosis of sickle cell anemia and $\beta$-thalassaemia with enzymatically amplified DNA and nonradioactive allele-specific oligonucleotide probes. $N$ Engl $\mathcal{F}$ Med 1988;319:537-41.

20 Zielenski J, Rosmahel R, Bozon D, et al. Genomic DNA sequence of the cystic fibrosis transmembrane conductance regulator (CFTR) gene. Genomics 1991;10:214-28.

21 Will K, Stuhrmann M, Dean M, Schmidtke J. Alternative splicing in the first nucleotide binding fold of CFTR Hum Mol Genet 1993;2:231-5.

22 Slomski R, Schlösser M, Berg LP, et al. Omission of exon 12 in CFTR gene transcripts. Hum Genet 1992;89:61512.

23 Bremer S, Hoof T, Wilke M, et al. Quantitative expression patterns of multidrug-resistance P-glycoprotein (MDR1) patterns of multildrug-resistancic fibrosis transmembrane and differentially spliced cystic fibrosis transmembrane conductance regulator mRNA

24 Hamosh A, Trapnell BC, Zeitlin PL, et al. Severe deficiency of cystic fibrosis transmembrane conductance ciency of cystic fibrosis transmembrane conductance regulator messenger RNA carrying nonsense mutations R553X and W1316X in respiratory epithelial cells of
patients with cystic fibrosis. $\mathcal{F}$ Clin Invest $1991 ; 88: 1880-5$.

25 Jones C, McIntosh I, Keston M, Ferguson A, Brock DJH Three novel mutations in the cystic fibrosis gene detected by chemical cleavage: analysis of variant splicing and nonsense mutation. Hum Mol Genet 1992;1:11-17.

26 Globerman H, Amor M, Parker KL, New MI, White PC Nonsense mutation causing steroid 21-hydroxylase deficiency. $₹$ Clin Invest 1988;82:139-44.

27 Baserga SJ, Benz EJ. Nonsense mutations in the human $\beta$ 
globin gene affect mRNA metabolism. Proc Natl Acad Sci USA 1988;85:2056-60.

28 Kadowaki T, Kadowaki H, Recher MM, et al. Five mutant alleles of the insulin receptor gene in patients with genetic forms of insulin resistance. $\mathcal{F}$ Clin Invest 1990;86:254-64. stability: sequence alterations at either end of the lac $Z$ gene affect the rate of mRNA inactivation. $f$ Bacteriol 1991;173:2167-72.

30 Urlaub GM, Mitchell PJ, Ciudad CJ, Chasin LA. Nonsense mutations in the dihydrofolate reductase gene affect RNA processing. Mol Cell Biol 1989;9:2868-80. 